\title{
Saúde mental, cultura e arte: discutindo a reinserção social de usuários da Rede de Atenção Psicossocial
}

\section{Mental health, culture and art: discussing the social reinsertion of users of the Psychosocial Care Network}

\section{Ana Karenina de Melo Arraes Amorim' Ana Kalliny de Sousa Severo²}

\begin{abstract}
Resumo
Este estudo objetivou investigar a reinserção social de usuários da Rede de Atenção Psicossocial (Raps) a partir da participação em iniciativas culturais e artísticas existentes numa capital do nordeste brasileiro. Trata-se de uma pesquisa qualitativa realizada em duas etapas: uma de caráter exploratório descritivo na qual, por meio de entrevistas semiestruturadas, mapeamos as formas de participação dos usuários em iniciativas culturais e artísticas; e uma segunda etapa etnográfica, na qual acompanhamos os usuários que afirmaram participar de atividades artístico-culturais nas iniciativas por eles citadas. Discutem-se os dados em eixos temáticos construídos coletivamente com profissionais e usuários da Raps, de modo a produzir um espaço coletivo de reflexão e ações de desinstitucionalização. Defende-se a criação de espaços de convivência e trabalho com iniciativas artísticas e expressivas, bem como qualificação da Raps de modo a incluir estratégias intersetoriais de reinserção social e de territorialização do cuidado nos projetos terapêuticos e institucionais.
\end{abstract}

Palavras-chave: Saúde Mental; Cultura; Reabilitação Psicossocial.

\begin{abstract}
This study aimed to investigate the social reinsertion of users of the Psychosocial Care Network (Raps) through their participation in cultural and artistic initiatives existing in a capital city of northeastern Brazil. It is a qualitative research carried out in two stages: a descriptive exploratory stage in which, through semi-structured interviews, we mapped the forms of participation of users in cultural and artistic initiatives; and a second ethnographic stage, in which we accompanied the users who have claimed to participate in artistic and cultural activities in the initiatives they have cited. Data are discussed in thematic axes constructed collectively with the staff and users of the Raps, in order to produce a collective space for deinstitutionalization actions and reflection. It is defended the creation of spaces of coexistence and working with artistic and expressive initiatives, as well as the qualification of the Raps in order to include intersectorial strategies to promote the social reinsertion of users and the territorialization of care in therapeutic and institutional projects.
\end{abstract}

Keywords: Mental Health. Culture. Psychosocial Rehabilitation.

\footnotetext{
${ }^{1}$ Universidade Federal do Rio Grande do Norte, Natal, RN, Brasil. E-mail: akarraes@gmail.com

${ }^{2}$ Universidade Federal do Rio Grande do Norte, Natal, RN, Brasil. E-mail: akssevero@gmail.com
} 


\section{Introdução}

A saúde mental constitui um campo de estudos cujos paradigmas são constantemente modificados e novos saberes construídos. As críticas feitas no processo de reforma psiquiátrica são endereçadas principalmente à ciência positivista, que legitimou e autorizou o modelo asilar de tratamento dos sujeitos ditos "doentes mentais". No Brasil, esse movimento se intensificou a partir da década de 1970, por meio do Movimento dos Trabalhadores da Saúde Mental (MTSM), com críticas voltadas para os maus-tratos contra os portadores de transtornos mentais (Amarante, 2007).

A Reforma Psiquiátrica, portanto, tratase de um movimento histórico de caráter político, social e econômico que, historicamente, foi marcado pela tentativa de superação do modelo manicomial asilar, mediante as discussões pela reestruturação da assistência psiquiátrica no país (Hirdes, 2009). Nesse processo, deu-se a implantação de políticas de atenção à saúde mental, com a criação do primeiro Centro de Atenção Psicossocial (Caps) no ano de 1986, na cidade de São Paulo. No dispositivo Caps, o tratamento passa a ser norteado não mais pelo conceito de cura, mas de reabilitação psicossocial na qual o indivíduo, antes excluído e alienado de suas possibilidades, pode-se tornar sujeito de sua própria história a partir da reinserção nos diversos seguimentos sociais.

Quando consideramos o conceito de reabilitação psicossocial, há uma diversidade de concepções que se constituíram ao longo do processo de reforma psiquiátrica no Brasil. Inicialmente, temos a concepção de Pitta (1996), que entende a reabilitação psicossocial como um processo que facilita ao indivíduo, a despeito de suas limitaçooes, mais autonomia na vida social e comunitária. Em sentido mais amplo, Saraceno (1996) descreve a reabilitação psicossocial como exercício de cidadania e de contratualidade social estabelecida em esferas distintas e complementares, quais sejam: o habitar, a rede de relações sociais e o trabalho. Já para Hirdes (2001) a reabilitação psicossocial deve ser direcionada necessariamente para uma redução de estigma e preconceito, com o objetivo de promover a equidade e a oportunidade de inclusão na sociedade aos usuários de salde mental, indicando a necessidade de uma transformação social e cultural e não apenas do indivíduo.

O movimento de Reforma Psiquiátrica brasileira vem ampliando propostas de reabilitação psicossocial com base na desinstitucionalização reforçadas pelo movimento luta antimanicomial (Amarante, 2007). Esse projeto de mudança, representado em alguns estados da federação por projetos de lei, é o resultado de um dos mais importantes processos de mudança cultural para a sociedade brasileira no fim do século XX, que diz respeito a uma revisão dos aparatos científicos, administrativos, jurídicos e éticos, relacionados com a "doença mental". Para Mota e Barros (2008), esse processo, pelas questões relacionadas à inserção dos loucos no mundo, toma como tarefa principal a cidadania, entendida como projeto aberto às singularidades e especificidades de diversas formas de expressão humana. Pensar a reinserção social torna-se mais complexo, pois as pessoas com história de internação psiquiátrica vivem o conflito de não inserção no mundo do trabalho, justificada pela sua condição de saúde. 
Ainda sob essa mesma óptica, compreendemos que desinstitucionalização consiste num processo que busca construir uma sociedade que se fundamente na cidadania, na liberdade, no respeito às diferenças e que acredite na potência de vida de cada sujeito. Nessa perspectiva, a reforma psiquiátrica visa reinserir as pessoas com transtornos mentais na sociedade por meio de mecanismos legais, técnicoassistenciais e culturais que tratam o indivíduo com transtorno mental como sujeito de direitos (Branco Neto \& Lima, 2011). Hirdes (2009), por sua vez, aponta que na reforma psiquiátrica brasileira, a criação dos dispositivos em saúde mental e a inserção das ações de saúde mental na saúde pública possibilitaram "novas abordagens, novos princípios, valores e olhares às pessoas em situação de sofrimento psíquico, impulsionando formas mais adequadas de cuidado à loucura no seu âmbito familiar, social e cultural” (p. 304).

Caminhando nesse sentido, os dispositivos de saúde devem realizar a intermediação desses sujeitos com o mundo social e devem primar pela diversidade de iniciativas que contemplem os diferentes modos de existir das pessoas em sofrimento psíquico grave, inscrevendo-se no âmbito da cidade. As atividades realizadas pelos dispositivos de saúde mental devem ser estruturadas e desenvolvidas na dimensão do cotidiano pessoal e social de modo a atender as suas diferentes necessidades. Trata-se definitivamente de reconstruir todo o processo de transformação do manicômio desenvolvido ao longo de nossa história e que deixou sua marca em múltiplas dimensões: do microcosmo da relação terapêutica à dimensão de uma nova política de cuidado comprometida com o empoderamento dos sujeitos (Branco Neto \&
Lima, 2011). Para tanto, é preciso ter claro que os muros a serem demolidos são, sobretudo, aqueles que impedem a utilização de outros saberes e recursos para lidar com a loucura em nossa cultura (Amarante, 2007; Amarante \& Costa, 2012; Hirdes, 2009).

Com esses fundamentos, foi instituída a Rede de Atenção Psicossocial (Raps) como novo arranjo organizativo dos serviços de saúde, que inclui os dispositivos sanitários em seus diferentes níveis de complexidade e densidade tecnológica capazes de atender às diferentes necessidades de atenção dos usuários do Sistema Único de Saúde (SUS) portadores de transtornos mentais e ou com problemas decorrentes do uso de álcool e outras drogas, bem como as iniciativas articuladas com outros setores (cultura, lazer, esporte, moradia, etc.) que promovam efetivos processos de reinserção social (Brasil, 2011ª).

De acordo com Azevedo (2010), a busca por parceiros em outros setores não sanitários é extremamente importante para a prática de reinserção na sociedade. No campo da cultura e da arte, por exemplo, encontram-se potentes aliados nos processos de reinserção social, uma vez que na arte o ser humano se reconhece e expressa seu poder criativo e pode, por intermédio dela, ter reconhecimento social. Nesse sentido, os Centros de Convivência e Cultura (Ceccos) têm se revelado como dispositivos fundamentais e espaços de sociabilidade, produção cultural e intervenção na cidade de modo articulado com os outros dispositivos da Raps (Ferigato, 2013).

Assim, os novos serviços de saúde mental foram se ampliando ao longo dos anos e abarcando áreas cada vez mais abrangentes da vida de seus usuários, transformando, assim, seus 
projetos de tratamento em projetos de vida, em que a clínica transforma-se em assistência e em intervenção no que diz respeito à sociabilidade e à vida na cidade. Nesse sentido, Rotelli, Leonardis e Mauri (2001) nos fazem ver que concretamente se transformam os modos nos quais as pessoas são tratadas para transformar o seu sofrimento, porque a terapia não é mais entendida como a perseguição da cura, mas como produção de vida, de sentido, de sociabilidade na utilização dos espaços coletivos de convivência.

Ao falar das experiências envolvendo arte, cultura e saúde mental, Amarante e Torre (2017) afirmam que elas estariam realizando rupturas significativas ao paradigma psiquiátrico, pois têm possibilitado a ampliação dos espaços de cidadania e circulação social das pessoas em sofrimento psíquico grave. Faz-se necessário, portanto, o reconhecimento da necessidade da presença da cultura e da arte nos contextos do cuidado em saúde mental, efetuando-se, dessa forma, por meio da busca de modos mais desinstitucionalizantes e transformadores de lidar com o fenômeno da loucura e do sofrimento psíquico, direcionados a novas formas de promover assistência, constituídas de outras experiências não restritas aos espaços dos serviços. Isso por que "é através da cultura, tomada na sua pluralidade, que grupos e pessoas inventam modos criativos de inscrever a loucura em um outro lugar, estabelecendo uma linguagem que abra espaços de jogos à própria diversidade da loucura" (Nunes, 2009, p. 38).

Para Amarante (2007, p. 63), o processo de desinstitucionalização "se constitui enquanto entrelaçamento de dimensões simultâneas, que ora se alimentam, ora são conflitantes; que produzem pulsações, paradoxos, contradições, consensos, tensões". Dessa forma, o processo social complexo de desinstitucionalização se produz nas dimensões teórico-conceitual; técnico-assistencial; jurídico-política e sociocultural. Dentre elas, a dimensão sociocultural diz respeito a "[...] todo o conjunto de transformações e inovações anteriores [que] contribuem para a construção de um novo imaginário social em relação à loucura e aos sujeitos em sofrimento, que não seja de rejeição ou tolerância, mas de reciprocidade e solidariedade" (Amarante, 2007, p. 73). Assim, identificar estratégias de aproximação e promoção das expressões culturais que integrem a pluralidade cultural, promovendo a reinserção de pessoas com transtornos mentais no âmbito da cultura, é fundamental, pois é nele que a arte ignora a diferença entre sanidade e loucura (Amarante \& Lima, 2008). Assim, as experiências mais recentes têm apontado para um descolamento da arte como dispositivo estritamente terapêutico, e se tornado uma estratégia de produção de projetos de vida (Amarante \& Torre, 2017). Pode-se conceber a arte como ingrediente importante na produção de saúde e vida desses sujeitos, com a da qual a loucura pode tornar-se força biopolítica, exigindo a construção de "dispositivos multifacéticos ao mesmo tempo, políticos, estéticos, clínicos na reinvenção das coordenadas de enunciação da vida" (Pélbart, 2013, p. 37).

A arte e a cultura compõem-se como dimensão estratégica, uma vez que diz respeito ao envolvimento da sociedade na discussão da reforma psiquiátrica com o objetivo de provocar o imaginário social a refletir sobre o tema da loucura, além da viabilização de outras atividades 
e iniciativas culturais e artísticas das pessoas em sofrimento psíquico.

No entanto, atualmente, um dos grandes desafios está na concretização de políticas e iniciativas voltadas para a reinserção social e construção de alternativas e espaços concretos que viabilizem a circulação dos usuários na vida social e seus projetos de vida, bem como garantam a eles o exercício da cidadania para além dos serviços de saúde, a semelhança dos Centros de Convivência e Cultura. No Nordeste brasileiro, são poucas as iniciativas de economia solidária e geração de renda na saúde mental e a maioria dos Centros de Convivência em funcionamento no país estão situados na região Sudeste (Brasil, 2011b). A escassez de dispositivos e iniciativas como esses indicam a precariedade do cenário de desinstitucionalização em saúde mental na região quando comparada a outras regiões do país.

A maioria das pesquisas existentes no Brasil relativas à interface arte, cultura e saúde mental produzem informações sistemáticas sobre esse quadro a partir da realidade das regiões Sudeste e Sul do país, de modo que não temos um quadro real da realidade regional e local. Por isso, percebemos a necessidade de investigações que produzam conhecimento sobre as iniciativas existentes, suas características e peculiaridades no cenário local e, assim, fomentar, incentivar e orientar a busca de sustentabilidade e a construção de novas estratégias de reinserção social de usuários no campo da saúde mental na região.

Diante desse cenário, realizamos um estudo com o objetivo de investigar a reinserção social de usuários da Rede de Atenção Psicossocial (Raps) numa capital do Nordeste brasileiro por meio da participação em iniciativas culturais e artísticas, de modo a identificar os espaços em que essas iniciativas se desenvolvem na cidade e conhecer as formas de inserção e participação de usuários no cenário cultural e artístico da cidade em sua relação com os seus projetos terapêuticos e de vida dos usuários da Raps, no sentido de contribuir para o processo de desinstitucionalização.

\section{Método}

A investigação consistiu numa pesquisa qualitativa e teve como fundamento metodológico a etnografia, compreendida como um método no qual os processos de construção teóricas, coleta de dados e registro se dão ao mesmo tempo, sendo um processo que envolve e exige sensibilidade reflexiva (Caprara \& Landim, 2008). Tal metodologia lançou mão de alguns instrumentos, tais como o diário de campo, no qual o pesquisador registra suas observações, sentimentos, experiências no momento que está em campo.

Assim, com base nessa perspectiva teórico-metodológica, desenvolvemos um trabalho de pesquisa, durante 18 meses, em duas etapas que envolveram, respectivamente, a realização de entrevistas semiestruturadas individuais e a etnografia propriamente dita com usuários da Raps que afirmaram participar de iniciativas culturais e artísticas na cidade.

A primeira etapa da pesquisa contou com a colaboração das equipes de cinco serviços da Raps (dois Caps Ad, um Caps II, um Caps III e um ambulatório de saúde mental) e participação ativa e colaborativa de usuários participantes que nos conduziam a outros possíveis entrevistados. Os critérios de inclusão foram: ser usuário da 
Raps local há pelo menos um ano; ter mais de 18 e desejar participar voluntariamente da pesquisa. Os critérios de exclusão para esse grupo foram: encontrar-se em crise psiquiátrica, com prejuízos cognitivos que inviabilizem a entrevista de pesquisa; ter menos de 18 anos; frequentar um serviço da Raps há menos de um ano.

Foram feitas 88 entrevistas semiestruturadas, com roteiro de perguntas previamente elaborado. Essa quantidade de participantes $\mathrm{da}$ pesquisa foi definida aleatoriamente e o procedimento de amostragem foi proposital por saturação, de acordo com os objetivos e o propósito deste estudo. Ou seja, a partir da visita aos serviços, foram convidados a participar da pesquisa os usuários que desejavam e que foram sendo indicados por outros usuários participantes e pelos profissionais do serviço. E quando percebemos a saturação nas respostas, essa etapa foi encerrada.

As entrevistas nos permitiram mapear 28 iniciativas de arte e cultura da qual participam usuários da Raps. No entanto, apenas 10 dessas iniciativas eram frequentadas com certa regularidade pelos usuários no momento da entrevista. Com base nessa informação, demos início ao acompanhamento etnográfico no cotidiano dos usuários em sua participação nessas iniciativas. Assim, ao longo de cinco meses, acompanhamos os usuários em atividades culturais e artísticas desenvolvidas em igrejas (católicas e pentecostais), casas de show, clubes e centros de lazer e esporte.

Como forma de registro da experiência etnográfica, produzimos diários de campo, o que nos permitiu uma aproximação da vivência cotidiana de campo e, ao mesmo tempo, possibilitou refletir sobre o processo de participação articulando com o que foi documentado, assim, possibilitando “desnaturalizar a 'neutralidade' do pesquisador, expondo suas experiências vividas no cotidiano, deparando-se com as fragilidades institucionais concretas" (Lourau, 1993, p. 79).

Como forma de fazer uma devolutiva da pesquisa realizada, construímos um processo de análise e discussão dos dados produzidos com os próprios usuários em grupos de diálogo coletivo, nos quais tinham voz os próprios participantes deste estudo, bem como usuários que eventualmente se mostraram interessados em participar do grupo mesmo não tendo sido entrevistados. Os grupos eram realizados na universidade e em encontros semanais, no formato de rodas de conversa, nas quais usuários e profissionais da Raps participaram com os pesquisadores desse processo de construção coletiva da análise dos dados da pesquisa.

A partir desses encontros, construímos eixos analíticos sobre os discursos dos participantes de cada uma das etapas da pesquisa e focalizamos aqui a discussão dos dados da primeira etapa da pesquisa.

Ressaltamos que os aspectos éticos de pesquisa com seres humanos foram respeitados, garantindo-se o sigilo das identidades dos participantes, bem como livre consentimento declarado por escrito pelos sujeitos que voluntariamente participaram, antes da realização de todos os procedimentos descritos.

\section{Resultados e discussão}

Nossas observações do cotidiano dos usuários dos serviços de saúde mental, bem como de sua participação e circulação em iniciativas de 
arte e cultura do referido município, indicaram o escasso envolvimento destes com iniciativas dessa natureza. Com a metodologia escolhida, foi-nos possível conhecer a rotina dos usuários, seus principais interesses no dia a dia, suas principais escolhas dentre as iniciativas de arte e cultura existentes, bem como suas histórias e projetos de vida. A discussão dos resultados ocorreu em diferentes eixos temáticos que trazemos a seguir.

\section{O cotidiano em seus limites e possibilidades}

Ao longo da pesquisa, deparamo-nos com as relações de dependência dos usuários com o serviço substitutivo, sendo este por vezes o único local onde o usuário realiza qualquer atividade fora de seu domicílio em seu cotidiano. Em alguns depoimentos, evidenciamos a não territorialização das práticas de cuidado pelos serviços substitutivos, produzindo o processo de isolamento social dos usuários, expressos em um cotidiano construído a partir da rotina institucional dos serviços, na contramão do que seriam efetivos processos de desinstitucionalização.

Meu dia a dia é as atividades que a gente faz. Tem de artesanato, tem leitura, oficina de leitura, tem atividade física, são várias, né?

Entrevistador: e fora do Caps, o que faz? Fora do Caps, pra ser sincero, eu não faço nada. É que eu sou aposentado, aí eu não faço nada. (Entrevistado 34 Caps Ad)

Ao chegar hoje ao Caps, encontro M. sentado no banco próximo à farmácia e percebo que está pensativo. Aproximo- me dele e cumprimento: “como está, M.?” Ele responde que está meio deprimido porque gostaria de ir ao cinema, que fazia muito tempo que não ia, mas que sua irmã não permitia que ele fosse sozinho e nem ia com ele. - "Ela tem medo que eu surte no meio da rua", diz ele. (Extrato de diário de campo Caps III)

Atualmente, estamos vivenciando um novo cenário da Reforma Psiquiátrica brasileira, no qual a oferta de cuidados extra-hospitalares é predominante. Porém, sabemos que as práticas de controle e normatização ainda se encontram enraizadas no cotidiano desses serviços, de tal forma que a sua manutenção, que por vezes aparece de maneira tão sutil, expressa uma cultura manicomial, dos nossos manicômios mentais (Pélbart, 1990). Assim, produzir interferências nesse âmbito é algo que parece ser difícil, visto que por vezes os próprios usuários do serviço encontram-se envoltos nessa lógica, indicando a produção de novas ordens de cronicidade no interior dos serviços (Barros, 2003).

A rede de serviços substitutivos conceitualmente deveria estar integrada com outros equipamentos sociais presentes no território, de modo a promover reinserção social. Para Giovanella e Amarante (1994), o território é entendido como elemento central na construção de estratégias para o planejamento em saúde mental. No território encontram-se as necessidades das pessoas que devem ser atendidas pelos serviços comunitários, além das singularidades dos territórios onde se constituem em suas histórias sociais, políticas e econômicas de ocupação e usos dos espaços (Lima \& Yasui, 
2014). A partir dessas necessidades e histórias, é que precisam ser criadas tantas estratégias quantas forem necessárias para um cuidado efetivo (Severo, 2014). Observamos atualmente serviços fechados em suas rotinas, que não se comunicam com os demais dispositivos do território capazes de possibilitar o trânsito dos usuários na vida que pulsa na cidade.

Assim, muitos dos usuários, quando convidados a relatar um pouco sobre sua rotina, afirmaram ter seu dia a dia entre o serviço e a sua residência, não citando quaisquer atividades fora desses âmbitos. Ainda em referência às atividades rotineiras, costumavam citar as atividades domésticas e de higiene pessoal, bem como a frequência com que participavam de atividades nas igrejas, como evidente em depoimentos como este:

Em casa? Em casa eu vou pra casa do povo, eu vou lavar os prato, vou fazer comer, lavar roupa, vou conversar, vou dormir nas casa do povo. [...] eu vivo dentro de casa, o pessoal nem me conhecia. Vou lavar roupa, vou cozinhar, vou fazer o mandado [...] eu frequento a igreja católica também. (Entrevistado 15 - Caps III)

A ausência de diálogo entre as atividades desenvolvidas pelos serviços comunitários de saúde mental e as necessidades e/ou desejos dos usuários estimula a dependência dos usuários em relação aos serviços substitutivos, produzindo a cronificação e um trânsito restrito no circuito especial (rede especializada de serviços de saúde mental - domicílio). Algumas propostas de desinstitucionalização, ao resultarem na cronificação, apontam a tentativa fracassada de liberar a Psiquiatria de sua relação histórica com a justiça e o controle social, enfatizando sua vocação terapêutica (Severo \& Dimenstein, 2011). Nesse sentido, podemos afirmar que estamos vivenciando, no contexto estudado, um modelo de atenção no qual as práticas de cuidado são restritas aos serviços de saúde e não fazem acontecer um processo de desinstitucionalização que ultrapasse as fronteiras sanitárias (Dimenstein \& Liberato, 2009). Ressaltamos assim a importância de que os serviços substitutivos trabalhem na lógica do território vivo e relacional, como apontado por Lima e Yasui (2014, p. 603).

Organizar um serviço que opere segundo a lógica do território é encontrar e ativar os recursos locais existentes, estabelecendo alianças com grupos e movimentos de arte ou com cooperativas de trabalho, para potencializar as ações de afirmação das singularidades e de participação social. Para tanto, é preciso criar uma intensa porosidade entre o serviço e os recursos do seu entorno. Significa, também, especialmente nos locais precários e homogeneizados, criar outros recursos, inventar e produzir espaços, ocupar o território da cidade com a loucura.

Além disso, no cotidiano, alguns usuários frequentam igrejas e estas são em sua maioria pentecostais ou católicas, indicando uma tendência já apontada na literatura e a influência de certas expressões religiosas na vida cultural dos usuários (Murakami \& Campos, 2012; Nunes, 2009). No entanto, poucos são os usuários que investem em iniciativas de arte e cultura, o que justificam a partir de algumas dificuldades relativas ao próprio processo de adoecimento; aos 
limites e mudanças fisiológicas colocados pelo uso de psicotrópicos e que interferem no cotidiano de atividades; a falta de informação sobre inciativas dessa natureza; a falta de motivação; aos limites impostos pela família e, sobretudo, por se sentirem vítimas de preconceitos nos diversos espaços sociais, o que os inibem de participar da vida pública, tal como fica evidente nas entrevistas e conversas:

Praticamente eu não faço nada, eu só fico em casa. Tomo a medicação e fico em casa. Porque eu não tenho condições de fazer nada, é, tomo a medicação forte, e eu não posso, não tenho força de fazer nada. (Entrevistado 1 - Caps III)

Assim, em casa eu não faço nada, porque não deixam eu fazer, ficam dizendo que eu sou inutilizada, não tenho capacidade, entendeu? Isso dá um complexo muito grande de inferioridade. [...] $\mathrm{Na}$ rua vejo que fazem piada [pausa]. Ai, isso dói, machuca, né? Pode ser que pra eles seja normal, mas pra mim machuca. (Entrevistada 13 - Caps III)

Hoje na roda de conversa da qual participamos S. fala de seus sonhos: quer assistir a um show de música "de verdade", fora da igreja e ter uma banda. Mas diz que se sente incapaz para fazer isso e que não sabe bem onde a música acontece na cidade. Fico comovida quando ele diz que se conforma em ouvir seu rádio e sonhar em estar lá. (Extrato de diário de campo - Caps II)
A partir desses depoimentos, vemos que a ampliação da vida para além do circuito casaserviço passa necessariamente pela desconstrução dos aspectos relativos ao adoecimento, ao uso de medicação e, sobretudo, à transformação dos modos de ver e dizer a loucura na nossa cultura. Os limites e dificuldades colocados por essa cultura para as pessoas com transtornos mentais nos indica que o trabalho de base a ser feito é na vida pública, na cidade, de modo a produzir transformação nas vidas singulares.

\section{A história de vida e as rupturas a partir da experiência da loucura}

Dentre as atividades que eles já participaram no passado, verificamos que a maioria dos usuários realizavam algum tipo de atividade, relacionadas a atividades esportivas, ao trabalho, bem como as atividades artísticas e/ou culturais. No entanto, devido às dificuldades já discutidas, atualmente eles não participam mais.

Constatamos também que muitos dos usuários entrevistados disseram que nunca participaram de atividades voltadas para a arte e cultura da cidade, além daquelas que já tiveram algum envolvimento dentro dos serviços de saúde mental, como afirmam quando indagados sobre sua participação em iniciativas de arte e cultura dentro dos serviços e fora deles.

A relação entre o antes e depois da experiência com a loucura e consequente diagnóstico psiquiátrico também é referida nos depoimentos. Assim, antes do processo de adoecimento, metade dos entrevistados referiram participar de iniciativas culturais, esportivas e artísticas: 
Quando eu não tinha este problema psiquiátrico. Ia pra dança no projeto de um vereador. (Entrevistada 24 - Caps II).

Não vou mais para lugar nenhum. Porque eu fiquei muito doente. Porque eu tô [sic] com síndrome do pânico, tenho medo de sair de noite. (Entrevistado 24 - Caps III).

Assim, ainda que haja a evidente falta de acesso à vida cultural pelos seguimentos sociais menos favorecidos, no caso das pessoas com transtornos mentais em situação de pobreza (como é o caso dos entrevistados), há ainda a ruptura com a vida social produzida a partir da experiência com a loucura. Essa experiência inaugura na vida dos sujeitos uma série de impossibilidades e a conhecida "carreira do doente mental", acarretando na institucionalização do sujeito e privatização de sua vida, que devem consistir no objeto mesmo do cuidado e das intervenções no processo de desinstitucionalização (Amarante, 2007).

Grande parte dos entrevistados tiveram história de internação em instituição psiquiátrica antes de integrar a Raps. Barros (2003) aponta que tal ruptura na vida das pessoas com história psiquiátrica se dá pela repercussão negativa do modelo hospitalocêntrico e da desarticulação da rede de saúde mental, produzindo novas cronicidades, uma vez que na Raps há novas "portas de entrada" e poucas "portas de saída". Assim, os então "pacientes" e agora "usuários" da Raps são postos como seres passivos diante dos desafios de produção de novas subjetividades (Barros, 2003).
Severo e Dimenstein (2011) ainda ressaltam que tais cronicidades se manifestam na paralisação dos usuários nos serviços de saúde mental, da dificuldade de produzir ações fora dos muros desses serviços, de inventar novas relações e sociabilidades na comunidade e de espaço urbano para as pessoas que sofrem de transtornos mentais.

Além disso, vimos que outras questões se apresentam nesse processo de desinstitucionalização, como é o caso da relação com o trabalho. Nas entrevistas, a questão do trabalho aparece como uma experiência do passado, com a qual se veem impossibilitados de se relacionar na atualidade dadas as dificuldades colocadas pelo adoecimento e sua marca da incapacidade. Além do trabalho, a vida na cidade, as relações com atividades de lazer também foram rompidas, assim como a relação com os diferentes espaços da cidade, tendo que criar formas de se relacionar com essas atividades que sejam mais “aceitáveis” para sua nova condição.

Assim, a partir das histórias de vida dos entrevistados, verificamos que a condição de vida de muitos ainda está atrelada ao processo de institucionalização e a vida "antes da doença", de tal maneira que muitos deles sempre se remetiam à vida passada como se depois do adoecimento a vida tivesse passado por um congelamento e ruptura. Isso se revela quando constatamos que, dos 88 entrevistados, apenas 11 participam atualmente de alguma atividade envolvendo arte e cultura fora da rede de serviços, em espaços de cultura e lazer no município.

Os usuários com os quais realizamos a etnografia, de outro modo, relataram que a doença não é mais impedimento para a reinserção, colocando outros fatores como 
impedimento para a participação em atividades na cidade, fora do circuito casa-rede de saúde, tais como, a condição econômica, devido ao alto custo das atividades culturais da cidade; e a experiência de preconceito vivido ou de medo de viver o preconceito relativo ao fato de ser portador de um transtorno mental grave e ser "visto como louco". A experiência do estigma da loucura se alia à questão da desigualdade social, que historicamente caminham juntas no mundo da exclusão. Aliança que as práticas de reinserção social pretendem desfazer.

Severo e Dimenstein (2009) afirmam que, a partir da culpabilização que recai sobre a doença e que se situa no próprio indivíduo, as expectativas de vida antes da crise psiquiátrica são desfeitas e as práticas de vida movimentam-se em função da nova condição. Isso é perpetuado pela bioidentidade de ser uma pessoa doente e de produzir a vida em função da busca de uma normalidade instituída socialmente. A pessoa com transtorno mental inicia sua carreira de institucionalização ao infringir normas sociais, em nome da manutenção de um ideal de normalidade e de bem-estar (Basaglia, 2005). Essa carreira inclui não apenas a institucionalização definida dentro dos hospitais e serviços de saúde, mas no meio social, onde existe estigma que produz formas de vida em função dele (Severo \& Dimenstein, 2009).

No entanto, alguns dos usuários que participam de inciativas fora da rede o fazem pois encontraram formas de enfrentar o estigma ligado à imagem do louco e dos sintomas a partir do apoio recebido na família, indicando que é possível reinventar a vida por meio de ações voltadas para a produção de arte e cultura, capazes de redefinir identidades, produzindo novas relações sociais, desde que encontrem redes de apoio social. Amarante e Torre (2017) ressaltam a importância da participação dos usuários em experiências de trabalho e economia solidária e também em experiências de arte e cultura na Saúde Mental, pois nestas eles tendem a se expressar e se identificar não mais a partir do lugar da doença, mas do lugar de sujeitos de direitos, com experiências válidas e capacidades reconhecidas socialmente. Deixam de se reconhecer a partir de um diagnóstico psiquiátrico para relacionar-se socialmente e apresentar-se como artista ou produtor cultural, como trabalhador de um projeto coletivo ou, ainda, como militante de movimentos sociais. (p. 766)

Dessa forma, é importante nos indagarmos se as ações de reinserção efetivamente têm produzido formas de enfrentamento ao preconceito e à segregação social e econômica vivida pelos usuários da Raps, de modo geral, e fortalecermos iniciativas de geração de renda, de arte e cultura que propiciem o rompimento da experiência do estigma.

\section{Projetos de vida e a reinserção social em análise}

A partir da análise dos dados, foi possível verificar também aspectos relacionados aos projetos de vida que dão sentido à existência desses usuários. No entanto, embora se perceba que após o adoecimento muitos deles pararam de realizar quase todas as atividades que participavam de seus projetos de vida, com a experiência do adoecimento sustentam alguns dos velhos projetos ou redefinem seus projetos de vida que foram se revelando ao longo das 
entrevistas e da etnografia realizada. Em algumas falas isso fica evidente:

Meu sonho era tocar, tocar num conjunto, tocar violão, já cheguei a tocar uma gaita, meu sonho era aprender a tocar. Mas agora está difícil (Entrevistado 78 - Ambulatório)

Eu gostaria de fazer o teatro, quando tiver oportunidade, eu vou entrar no teatro. Assim, se eu tivesse alguma chance, né? (Entrevistado 57 - Caps $\mathrm{AD})$

Nos depoimentos, foi possível constatar que apesar da existência desses projetos muitos destes foram "abandonados", não apenas por causa das rupturas analisadas anteriormente, mas porque as práticas de cuidado e de reinserção social realizadas dentro dos serviços não criam as condições necessárias para que esses projetos tenham andamento, ganhem sentido em suas possibilidades nas vidas dos usuários. Os serviços de atenção psicossocial oferecem atividades envolvendo os interesses dos usuários, mas que não fazem "sentido" para eles como efetivas contribuições aos seus projetos de vida. Muitos relatam estarem enfadados ou terem "perdido o gosto" pelas atividades propostas nas oficinas terapêuticas que se restringem ao espaço do serviço e que, não raro, infantilizam os usuários quando desconectadas das suas atividades laborais anteriores ou de suas capacidades produtivas efetivas:

Aqui é só pintar, pintar, pintar. Eu não gosto de pintar. Daí não participo. Aqui era pra ter aula de música. Às vezes acho que eles aqui estão mortos. Porque não tem oportunidades e não tem o desejo no cérebro e no coração para dançar e cantar. Quem não faz isso está morto. (Entrevistado 19 - Caps III)

Olhe... Só fazer desenho. Porque tá com três anos que eu tô participando só da reunião terapêutica e do grupo. Não, não é minha praia não. Não aguento mais só desenhar! (Entrevistado 84 Ambulatório)

E a gente viver aqui dentro só dependendo do Caps, também num é muito bom, e se torna uma rotina, e essa rotina se torna chata, às vezes. (Entrevistado 28 - Caps AD)

Ao refletirem sobre essas experiências da rotina institucional que não permite que eles possam ir além da oferta do serviço que é desconectada de seus projetos, alguns entrevistados demonstram a mortificação e a mecanização dos corpos produzidas, num regime biopolítico que reproduz aquele da vida social capitalística em sentido amplo (Pélbart, 2003).

Também foi possível refletir sobre as práticas de cuidado dentro desses serviços de atenção psicossocial de modo que possam se converter em intercessoras nos projetos de vida, no sentido colocado por Ayres (2004), ao afirmar que a produção de saúde está diretamente relacionada aos projetos de vida de cada sujeito atendido em seus horizontes normativos. Sensível a essa perspectiva é que a reinserção social deve fundamentar os projetos institucionais dos 
serviços da Raps nos quais as oficinas terapêuticas, a criação de cooperativas de geração de renda e os diversos espaços de sociabilidade promovidos a partir deles ganham sentido de desinstitucionalização, mesmo com os desafios postos. Desafios que a etnografia nos permitiu perceber com mais sutileza:

M. foi o primeiro usuário a nos apresentar o espaço frequentado por ele: a Igreja Bom Jesus das Dores, local onde participa do grupo de música existente há cinco anos. Sua participação ocorreu por meio da intervenção feita por uma tia com o líder do grupo. Considerando sua habilidade para tocar bateria, ele frequenta o grupo há seis meses. Percebemos que sua participação é pontual, porém o local é considerado por M. como um espaço de expressão, apesar de sua aparente timidez e reclusão no grupo. No entanto, ficou claro que a música foi um recurso encontrado por ele para dar continuidade a sua vida [...]. Apesar disso, a interação entre M. e o grupo é muito restrita a cumprimentos. A distância e o isolamento de M. me incomodou profundamente. Principalmente depois que ele falou se manter numa posição afastada no grupo e confessou que os integrantes do grupo não sabem que ele é usuário do Caps, e ele diz que prefere assim. (Extrato de diário de campo - Etnografia com M.)

Assim, vemos o desafio da inserção e produção de vida em função dos preconceitos relativos à loucura e pensamos que a mediação por meio do trabalho territorial, como indicado por Lima e Yasui (2014), pode criar para os usuários outras condições de sociabilidade e cuidado nos espaços em que circulam ou desejam circular.

Com os encontros de construção coletiva da análise que promovemos e na devolutiva realizada em um dos serviços, tornou-se possível explicitar esse campo de tensão produzido pela falta de um trabalho territorial, que enfraquece o processo de reinserção. Num dos encontros, um entrevistado afirma: "A vida da gente não sai do Caps. A arte que a gente faz nasce no Caps e morre no Caps" (entrevistado 24 - Caps III).

A fala dispara um processo de reflexão coletiva que reconhece como os trabalhos realizados nas oficinas nos Caps não têm conduzido à efetiva reinserção social, ultrapassando os muros dos serviços e ocupando a cidade.

Com a etnografia, observamos a importância da utilização das iniciativas mapeadas como forma de intervenção no campo da saúde mental para os processos de desinstitucionalização não reduzidos à desospitalização, bem como para a proposição de novos olhares acerca da loucura. As iniciativas fazem sentido na construção de vida de cada sujeito, compondo os projetos de vida de cada um. Ser parte de uma banda da igreja, ir ao forró, frequentar o culto, participar da aula de dança são atividades de vida e promovem encontros entre pessoas em sofrimento psíquico e a sociedade, em 
efetivo exercício da cidadania, expressão de liberdade e convivência em cenários culturais e artísticos. Segundo Rauter (2000), o trabalho e a arte podem ser grandes "vetores de existencialização" que conferem sentido aos processos de desinstitucionalização.

As oficinas, o trabalho e a arte podem funcionar como catalisadores da construção de territórios existenciais (inserir ou reinserir socialmente os "usuários", torná-los cidadãos...), ou de "mundos" nos quais os usuários possam reconquistar ou conquistar seu cotidiano [...] está se falando não de adaptação à ordem estabelecida, mas de fazer com que trabalho e arte se reconectem com o primado da criação, ou com o desejo ou com o plano de produção da vida. (Rauter, 2000, p. 271).

A investigação indica, assim, que se faz necessária a construção de estratégias de territorialização do cuidado capazes de possibilitar a invenção de novas relações e sociabilidades no espaço urbano, criando novos modos de existir. Essa necessidade existe por diversos motivos, dentre eles para que não haja continuidade da cronificação dos serviços provocada pela falta de articulação de diferentes serviços e apoios sociais, culturais e assistenciais que produz efeitos danosos, tais como a sobrecarga dos trabalhadores de saúde e a burocratização das práticas, como pudemos observar. $\mathrm{O}$ fomento à construção de redes territorializadas com múltiplas conexões pode ser capaz de romper com o circuito que se retroalimenta, causando a estagnação dos fluxos de experimentação e a reprodução de modos de relação homogêneos.

Para o processo de desinstitucionalização, é necessária a articulação com as iniciativas na cidade, de modo que os usuários não mais tomem o serviço como única possibilidade para as atividades de seu cotidiano. É necessário alargar a visão, ampliar o campo das possibilidades e auxiliar os usuários a reconhecerem-se parte da cidade, rompendo com os discursos e práticas de vigilância, de controle de excessos, de ajustamento do comportamento a uma normalidade "desejada" e consequente homogeneização das subjetividades.

A etnografia nos permite afirmar que a circulação na cidade produz uma dispersão dos mecanismos biopolíticos na sociedade que ora conduzem ao encarceramento, ora à liberdade. Dessa forma, sua capacidade de se lançar nas possibilidades da cidade poderia ser entendida como potência de vida, na luta pelo direito à desrazão (Pélbart, 1990).

Para tanto, é preciso considerar as relações micropolíticas institucionais no âmbito dos serviços, colocando-as em análise diante das tensões macropolíticas existentes. Isso ficou evidente na devolutiva da pesquisa a um dos serviços da Raps, quando foi possível escutar também os profissionais desse serviço a respeito do seu atual funcionamento. Nesse espaço, voltado para a discussão da nossa temática de pesquisa, os profissionais nos trouxeram a angústia vivenciada por eles pela ausência de recursos materiais e humanos que permitam um bom desenvolvimento das atividades, além da inexistência de espaços de supervisão como importante para colocar em análise o trabalho realizado e ir qualificando-o, sobretudo, no que diz respeito à construção de Projetos Terapêuticos Singulares que viabilizem a reinserção dos usuários. Além de superar a descontinuidade e fragmentação existente nas 
políticas públicas relacionadas ao campo da saúde mental e atenção psicossocial (Galvanese et al., 2016), torna-se importante investir na qualificação da atenção, de modo a possibilitar que os serviços produzam a vida "lá fora", em redes de conexão e diálogo nos diferentes espaços onde cada usuário circula e constrói sua vida, de modo a garantir a (des)construção permanente das práticas de cuidado de acordo com as necessidades específicas de saúde de cada usuário (Amorim \& Dimenstein, 2009; Severo, 2014).

Reconhecemos a existência de um campo de tensão entre os profissionais dos serviços substitutivos e alguns usuários, o que acaba por enfraquecer o desenvolvimento da reinserção social. Esse fato acaba por alimentar o modelo biomédico, que tende a impossibilitar o diálogo entre ambos, impedindo o avanço do processo de reforma psiquiátrica local e reproduzindo a lógica manicomial. Isso expressa ainda "a herança profundamente arraigada nos serviços e profissionais da preponderância do conhecimento biomédico e da disciplina e normatização dos usuários advindas do modelo manicomial" (Galvanese et al., 2016, p. 448). A carência de espaços coletivos de discussão e análise das práticas de desinstitucionalização na agenda da Raps produz situações de conflito que se acumulam no cotidiano institucional e reproduz um antagonismo: usuário e equipe migram como para um campo de batalha, investindo suas forças não mais na desinstitucionalização, mas na luta entre eles, exigindo o reconhecimento de ambas as partes da necessidade de se firmar uma aliança que resgate o sentido do trabalho na atenção psicossocial nos processos de desinstitucionalização.

\section{Considerações finais}

A proposta de investigação dos processos de reinserção social de usuários da rede de saúde mental de uma capital do Nordeste brasileiro, nos proporcionou refletir sobre o cenário da política de saúde mental nesse contexto, no que diz respeito a seus avanços e retrocessos, assim como nos muitos desafios que impedem a instalação e efetivação dos processos de desinstitucionalização.

Nessa direção, verificamos como são restritas as iniciativas artísticas e/ou culturais conhecidas pelos participantes da pesquisa, seja pela falta de informação a respeito e pelas limitadas condições econômicas deles, seja pela realidade de preconceito e estigmatização que ainda enfrentam na vida social. Não se fazem presentes nos discursos e nas observações feitas do cotidiano de usuários, redes de sociabilidade efetivas no processo de reinserção desses sujeitos, para além das relações familiares e estabelecidas dentro dos serviços de saúde mental.

Os desafios relatados pelos usuários e observados na experiência etnográfica com eles nos permitiram constatar que forças de diferentes naturezas impedem ou limitam a participação e efetiva reinserção social. Dentre elas, destacamos o fato de vivermos em uma sociedade em que a desconstrução de uma lógica manicomial está muito distante de se efetivar devido ao poder disciplinador existente nos diversos e limitados espaços por onde circulam esses sujeitos, na família, na comunidade e mesmo na rede sanitária. Num plano macropolítico, isso fica mais evidente, uma vez que não existem projetos e ou iniciativas promovidas pelas políticas públicas que possibilitem a reinvenção da vida em espaços fora 
dos limites sanitários, num desenho de rede e que contenha a ativa força das subjetividades singulares que não respondam mais à lógica homogeneizante e manicomial tão marcante na nossa sociedade.

De outro modo, pudemos observar como alguns usuários enfrentam cotidianamente os limites da lógica manicomial e criam estratégias desisntitucionalizantes para si mesmos, insistem em participar da vida social e buscam iniciativas de expressão construídas com seus familiares e comunidade, com apoio de alguns profissionais da Rede de Atenção Psicossocial, revelando que o processo de reinserção é possível, a despeito de todas as limitações ainda encontradas.

\section{Referências}

Amarante, P. (2007). Saúde Mental e Atenção Psicossocial. Rio de Janeiro: Fiocruz.

Amarante, P., \& Lima, R. (2008). Loucos pela diversidade: da diversidade da loucura à identidade da cultura. Relatório final. Rio de Janeiro, s.n.

Amarante, P., \& Costa, A. M. (2012). Diversidade Cultural E Saúde. Rio de Janeiro: Cebes.

Amorim, A. K. M. A., \& Dimenstein, M. D. (2009). Desinstitucionalização em saúde mental e práticas de cuidado no contexto do serviço residencial terapêutico. Ciência \& Saúde Coletiva, 14(1), 195-204.

Amarante, P., \& Torre, E. H. G. (2017). Loucura e diversidade cultural: inovação e ruptura nas experiências de arte e cultura da Reforma Psiquiátrica e do campo da Saúde Mental no Brasil. Interface:
Comunicação, Saúde e Educação, 21(63), 763774.

Ayres, J. R. C. M. (2004). Cuidado e reconstrução das práticas de saúde. InterfaceComunicação, Saúde, Educaşão, 8(14), 73-92.

Azevedo, E. B. (2010). Rede de cuidado na saúde mental: tecendo práticas de inclusão social no município de Campina Grande - PB. 144f. Dissertação de mestrado em enfermagem, Centro de Ciências da Saúde, Universidade Federal da Paraíba, João Pessoa, 2010.

Barros, R. B. (2003). Reforma Psiquiátrica Brasileira: resistências e capturas em tempos neoliberais. In Conselho Federal de Psicologia (Org.). Loucura, Ética e Politica: escritos militantes (pp. 196-206). São Paulo: Casa do Psicólogo.

Basaglia, F. (2005). Escritos selecionados em saúde mental e reforma psiquiátrica. Rio de Janeiro: Garamond Universitária.

Branco Neto, J. R. C., \& Lima, V. B. O. (2011). Reforma psiquiátrica e políticas públicas de saúde mental no Brasil: resgate da cidadania das pessoas portadoras de transtornos mentais. Direito \& Política, 1(1), 121-31.

Brasil, Ministério da Saúde. (2011a). Portaria $n^{o}$ 3.088, de 23 de dezembro de 2011. Institui a Rede de Atenção Psicossocial para pessoas com sofrimento ou transtorno mental e com necessidades decorrentes do uso de crack, álcool e outras drogas, no âmbito do Sistema Único de Saúde (SUS). Brasília, DF. 
Brasil. Ministério da Saúde. (2011b). Secretaria de Atenção à Saúde. Dapes. CoordenaçãoGeral de Saúde Mental, Álcool e Outras Drogas. Saúde Mental no SUS: as novas fronteiras da Reforma Psiquiatrica. Relatório de Gestão 20072010. Ministério da Saúde: Brasilia.

Caprara, A., \& Landim, L. P. (2008). Etnografia: usos, potencialidades e limites na pesquisa em saúde. Interface-Comunicação, Saúde, Educaşão, 12(25), 363-76.

Dimenstein, M., \& Liberato, M. (2009). Desinstitucionalizar é ultrapassar fronteiras sanitárias: o desafio da intersetorialidade e do trabalho em rede. Cadernos Brasileiros de Saúde Mental, 1(1).

Ferigato, S. H. (2013). Cartografia dos Centros de Convivencia de Campinas: produzindo Redes de Encontros. Campinas. 320f. Tese de doutorado em Saúde Coletiva, Departamento de Saúde Coletiva, Faculdade de Ciências Médicas, Universidade Estadual de Campinas (Unicamp).

Galvanese, A. T. C., Pereira, L. M. F., D’Oliveira, A. F. P. L., Nascimento, A. P.; Lima, E. M. F. A., \& Nascimento, A. F. (2016). Arte, saúde mental e atenção pública: traços de uma cultura de cuidado na história da cidade de São Paulo. História, Ciências, Saúde - Manguinhos, 23(2), 431452.

Giovanella, L., \& Amarante, P. (1994). O enfoque estratégico do planejamento em saúde e saúde mental. In P. Amarante. Psiquiatria Social e Reforma Psiquiátrica (pp. 113-148). Rio de Janeiro: Fiocruz.
Hirdes, A. (2001). Reabilitação Psicossocial: dimensões teórico-práticas do processo. Brasil: Edifapes.

Hirdes, A. (2009). A reforma psiquiátrica no Brasil: uma (re)visão. Ciência \& Saúde Coletiva, 14(1), 297-305.

Lima, E. de A., \& Yasui, S. (2014). Territórios e sentidos: espaço, cultura, subjetividade e cuidado na atenção psicossocial. Saúde debate, 38(102), 593-606.

Lourau, R. (1993) Análise Institucional e Práticas de Pesquisa. Rio de Janeiro: Ed. Uerj.

Mota, T. D., \& Barros, S. (2008). Saúde mental, direitos, cidadania: o escritório de advocacia como agência para inclusão social. Revista da Escola de Enfermagem da USP, 42(2), 220-226.

Murakami, R., \& Campos, C. J. G. (2012). Religião e saúde mental: desafio de integrar a religiosidade ao cuidado com o paciente. Revista Brasileira de Enfermagem, 65(2), 361367.

Nunes, M. O. (2009) O silenciamento da cultura nos (con)textos de cuidado em saúde mental. Cadernos Brasileiros de Saúde Mental, 1(2), 38-48.

Pelbart, P. P. (1990). Manicômio mental: a outra face da clausura. In A. Lancetti (Org.). Saúdeloucura 2 (pp. 130-138). São Paulo: Hucitec.

Pelbart, P. P. (2003). Vida capital: ensaios de biopolítica. São Paulo: Iluminuras.

Pelbart, P. (2013). O teatro da loucura. Poliética, 1(1), 119-129.

Pitta, A. (1996). O que é a reabilitação psicossocial no Brasil, hoje?. In A. M. 
Pitta, (Org.). Reabilitação psicossocial no Brasil (pp.19-26). São Paulo: Hucitec.

Rauter, C. (2000). Oficinas para quê? Uma proposta ético estético-política para oficinas terapêuticas. In P. Amarante (Org.). Ensaios: subjetividade, saúde mental, sociedade (pp. 267-277). Rio de Janeiro: Fiocruz.

Rauter, C. (2015). Arte, clínica e transdisciplinaridade. Polêmica, 15(3), 112. DOI: 10.12957/polemica.2015.1936210

Rotelli, F., Leonardis, O., \& Mauri, D. (2001). (Orgs.). Desinstitucionalização. São Paulo: Hucitec.

Saraceno, B. (1996). Reabilitação psicossocial: uma estratégia para a passagem do milênio. In A. M. Pitta (Org.). Reabilitação psicossocial no Brasil (pp.13-18). São Paulo: Hucitec.

Severo, A. K. S. (2014). A institucionalização da supervisão na Reforma Psiquiátrica brasileira: (re)produção de controles e desvios junto às equipes de saúde mental. Campinas. 259f. Tese de doutorado em Saúde Coletiva, Departamento de Saúde Coletiva, Faculdade de Ciências Médicas, Universidade Estadual de Campinas (Unicamp).

Severo, A. K., \& Dimenstein, M. (2011) Rede e intersetorialidade na atenção psicossocial: contextualizando o papel do ambulatório de saúde mental. Psicologia: Ciência e Profissão, 31(3), 640-655.
Severo, A. K., \& Dimenstein, M.. (2009). O diagnóstico psiquiátrico e a produção de vida em serviços de saúde mental. Estudos de Psicologia, 14(1), 59-67.

Recebido em: 12/08/2017

Aprovado em: 06/08/2018 